\title{
A third-party investigation of inpatient satisfaction with a tertiary hospital in People's Republic of China
}

This article was published in the following Dove Press journal:

Patient Preference and Adherence

Pan $\mathrm{Ke}^{1, *}$

Fengbo Jiang ${ }^{2, *}$

Dongmei $\mathrm{Wu}^{3, *}$

$\mathrm{Li} \mathrm{Ke}{ }^{2}$

Zi Lin ${ }^{2}$

Jia Jia ${ }^{2}$

Baoxia $\mathrm{Ye}^{3}$

Bing Liu'

'Health Management and Health Development Research Center of Hubei University of Medicine, Shiyan, People's Republic of China;

${ }^{2}$ Postgraduate Training Base of Hubei University of Medicine, Jinzhou Medical University, Jinzhou, People's Republic of China; ${ }^{3}$ Department of Cardiology Three Wards, Shiyan Taihe Hospital (The Affiliated Hospital of Hubei University of Medicine), Shiyan, People's Republic of China

*These authors contributed equally to this work
Correspondence: Bing Liu

Health Management and Health

Development Research Center of Hubei

University of Medicine, 30 South Renmin

Road, Shiyan 442000, People's Republic

of China

Tel +86 I38 7277 I527

Fax +867198892203

Email sy-lb@।26.com
Background: Conflicts between doctors and patients occur in People's Republic of China each year. Serious negative relationships between doctors and patients are a significant social problem. This study aims to evaluate the satisfaction of inpatients in a tertiary hospital through a third party and analyze the relationship between sociodemographic characteristics and overall satisfaction. Patients and methods: A cross-sectional investigation was conducted to obtain the demographic information and results for 20 items in an inpatient satisfaction questionnaire. A total of 872 inpatients were studied. Descriptive analysis was conducted using SPSS version 22.0 software. Independent sample $t$-tests and one-way ANOVA were used to compare the mean differences between groups. Multiple linear regression analysis was conducted to study the relationship between different demographic characteristics and overall satisfaction. $P$-values of $<0.05$ were considered significant. Matrix analysis was used to predict which of the 20 items had a higher priority for patient satisfaction.

Results: Among the respondents, valid questionnaires were completed by 872 patients, with a response rate of $94.47 \%$ (872/923). The hospital inpatient satisfaction score was $84.92 \pm 10.34$. Among the sociodemographic characteristics, education status, occupation, annual income, residence and frequency of visits were related to inpatient satisfaction and were statistically significant $(P<0.05)$. However, sex, age and marital status were not significantly different in terms of the inpatient satisfaction score $(P>0.05)$. Multiple linear regression analysis results showed that residence, age, occupation and education status were the factors affecting inpatient satisfaction. In further analyses, diet management, medical expenses, complaint management and hospital environment were in urgent need of improvement.

Conclusion: The overall level of inpatient satisfaction with this hospital seems to be acceptable, although areas for improvement remain.

Keywords: satisfaction, sociodemographic characteristics, importance matrix analysis, influencing factors

\section{Introduction}

In the era of planned economy in People's Republic of China, the doctor-patient relationship is harmonious. ${ }^{1}$ Since the 1980 s, the conflict between doctors and patients has been increasing year by year because violent conflicts caused by doctorpatient disputes have occurred from time to time. ${ }^{2}$ In the 21 st century, the deterioration of the relationship between doctors and patients in People's Republic of China has always been a hot spot of public concern. ${ }^{3}$ According to a survey conducted by the Chinese Medical Doctor Association in 2014, 62\% of physicians believe that the practice environment has not improved and $66 \%$ of doctors have experienced 
different levels of doctor-patient conflict, but the vast majority are occasional verbal violence $(51 \%) .{ }^{4}$ Conflicts between doctor and patient are mainly summarized as: doctor-patient contradiction, doctor-patient disputes and hospital violence. ${ }^{3,4}$ Hospital violence is the most powerful form of conflict between doctors and patients, deepen the contradiction between the doctors and patients and are even illegal. Previous research has shown that in the conflict between doctors and patients, $<20 \%$ is due to technical reasons and $80 \%$ of doctor-patient disputes are caused by medical service attitude, language communication, medical ethics and non-technical reasons. ${ }^{4}$

Patient satisfaction is considered an important tool for quality management of medical services. ${ }^{5}$ The investigation of patient satisfaction is a method of assessing the quality of care from the perspective of patients. Hospitals are facing doctor-patient conflicts that have intensified the need for the assessment of patient satisfaction, as improved patient satisfaction could effectively alleviate the conflicts between doctors and patients. ${ }^{6}$ Medical services are different from general market services, ${ }^{7}$ with information asymmetry, high risk, high expectations of patients and other characteristics. The cognition of patients, their psychological and emotion state, the prevalence of stress and the current tension in the doctor-patient relationship will have an irrational impact on evaluation of the medical services received. ${ }^{8,9}$

In 2000, Professor Bao Guoxian of Lanzhou University first proposed the concept of "third-party evaluation" in People's Republic of China: ${ }^{10}$ the first-party evaluation refers to the self-evaluation of the government department; the second-party evaluation refers to the government system, and the superior level evaluates the lower level, which is the internal evaluation. The third-party evaluation is the assessment conducted by third-party organizations that are independent of the government and its departments. It is also known as an external assessment and typically includes independent third-party evaluation and commissioned third-party evaluation. Li Qing, ${ }^{11}$ from the Department of Medicine of Peking University, proposed the establishment of a comprehensive supervision and evaluation system for hospitals with clear responsibilities as a third party. Kezhen and Tingfang proposed to establish a third-party evaluation and evaluation model and path for medical institutions suitable for domestic conditions, and provide theoretical support for promoting third-party evaluation models of medical institutions in People's Republic of China. ${ }^{12}$

Hospitals, patients and third-party organizations are independent of one another. ${ }^{13-15}$ In People's Republic of China, third-party investigators refer to investigators who are completely independent of hospitals and government agencies. ${ }^{16}$ Third-party investigators are mainly from professional data companies, market consulting companies and academic institutions. ${ }^{16,17}$ Investigators are not established within the evaluation object, and according to certain rules and methods, investigate the service level of the evaluated medical institutions and make a scientific and objective assessment of the hospital service level based on the survey results. ${ }^{17}$

Third-party evaluation of patient satisfaction started relatively late in the People's Republic of China. The earliest practice of evaluating patient satisfaction through third parties occurred at Shengjing Hospital of China Medical University in $2004 .{ }^{18}$ As the Chinese practice of third-party evaluation of satisfaction is not yet mature, some fields are still in the stage of exploration and constant improvement. To standardize third-party evaluations, the Chinese Health Management Department also carried out a series of reforms. The National Health Commission of the People's Republic of China published the "Action Plan for Further Improving Medical Services" on January 12, 2015. ${ }^{19}$ This action plan aims to evaluate the quality of hospitals through third-party review and to establish a three-level evaluation system of "results-process-structure" to narrow the perspective deviation and harmonious doctor-patient relationships.

Shiyan is located in the middle of People's Republic of China; at the end of 2017, the total registered population was $3,416,600$. The city has 58 hospitals, including 32 general hospitals, 8 Chinese medicine hospitals, 2 integrated Chinese and Western medicine hospitals and 16 specialized hospitals. ${ }^{20}$ Among them, there are six tertiary hospitals, such as the Taihe Hospital which is responsible for the treatment of serious and difficult diseases, research and teaching and medical training in the region.

However, the third-party patient satisfaction evaluation mechanism has not yet been established in the local hospitals. Thus, we consider it necessary to collect a substantial amount of valuable first-hand information about the scientific objectives in order to gain a systematic in-depth understanding of the status of medical services in the region. As a third-party evaluation institution, the center for Health Management and Development of Hubei University of Medicine recruits local college students and social part-time staff (who have no direct or indirect contact with hospitals and patients) as a third-party investigator to evaluate patient satisfaction in tertiary hospitals in the region. We analyzed the findings of the survey data to help hospitals improve management and patient experience. 


\section{Patients and methods}

This study was conducted in the clinical departments serving the hospitalized patients of Shiyan Taihe Hospital in the People's Republic of China from May 17, 2017 to June 10, 2017. This is a central hospital in the middle and western regions of People's Republic of China; it has 4,540 beds, 5,000 stuffs, 22 key clinical departments and 14 medical technology departments. According to the hospitalizations in 22 key departments provided by the hospital, the average number of hospitalizations was 3,500 . The sample size was calculated using the following formula:

$$
n=\frac{t^{2} \hat{\sigma}^{2}}{\Delta_{\mathrm{x}}{ }^{2}+\frac{t^{2} \hat{\sigma}^{2}}{\mathrm{~N}}}
$$

It was found to be $\mathrm{N}=3,500$, with a $95 \% \mathrm{CI}, t=1.96$, limit $\operatorname{error}\left(\Delta_{\mathrm{X}}\right)=0.1$ and population variance $\left(\delta^{2}=1.82\right)$; therefore, 923 patients were included. The inclusion criteria for the sampled inpatients are as follows: hospital stay of $>3$ days, face-to-face communication with the investigators so that patients can express subjective feelings autonomously (children under 12 years of age were represented by their parents) and signing an informed consent. Since we are conducting a third-party patient satisfaction survey, if we investigate the hospitalization of the hospital staff or their families in this hospital, it may affect the authenticity of the results, so we excluded the hospital staff or their family. This research procedure was approved by the Ethics Committee of the Taihe Hospital (Approval No 2017-TH-024). Each participant was allowed to participate in the study after reading the informed consent form and signing to confirm their participation; for those under 18, their parents signed and confirmed the participation. The distribution and sampling of the departments are shown in Table 1.

We used the "Inpatient Patient Satisfaction" questionnaire devised by Chongqing Zhidao Hospital Management corporation and the questionnaire was authorized by the corporation. The questionnaire consisted of two parts. Section 1 collected general information from the inpatients (sex, age, education status, occupation, marital status, annual income, residence and frequency of visits). Section 2 was composed of 20 items that focused on the inpatient experience: 1) the admission process; 2) the frequency of doctors' ward rounds; 3) the frequency of nurses' ward rounds; 4) emergency response; 5) transparency; 6) informed consent; 7) protection of patient privacy; 8) doctors' technical skill; 9) nurses' technical skill; 10) auxiliary examinations (eg, radiation, ultrasound, electrocardiogram); 11) health education; 12) doctors' attitudes toward service; 13) nurses' attitudes toward service; 14) overall service process; 15) complaint management; 16) medical expenses; 17) hospital

Table I Distribution of clinical departments and proportion of samples

\begin{tabular}{l|l|l|l|l}
\hline Number & Department & Average hospitalization (n) & Samples (n) & Percentage \\
\hline 1 & Vasculocardiology & 166 & 45 & 27.11 \\
2 & Gastroenterology & 147 & 43 & 29.25 \\
3 & Endocrinology & 92 & $37 j$ & 40.12 \\
4 & Hematology & 74 & 34 & 45.95 \\
5 & Nephrology & 98 & 38 & 38.78 \\
6 & Pneumology & 163 & 45 & 27.62 \\
7 & Oncology & 227 & 48 & 21.15 \\
8 & Neurology & 260 & 50 & 19.23 \\
9 & General surgery & 313 & 51 & 16.29 \\
10 & Orthopedics & 327 & 52 & 15.9 \\
11 & Plastic surgery & 78 & 34 & 43.59 \\
12 & Neurosurgery & 170 & 45 & 26.47 \\
13 & Thoracic surgery & 89 & 36 & 40.41 \\
14 & Urology & 75 & 34 & 45.33 \\
15 & Gynecology & 242 & 49 & 20.25 \\
16 & Pediatrics & 345 & 52 & 15.07 \\
17 & Otorhinolaryngology & 174 & 45 & 25.86 \\
18 & Geriatrics & 91 & 37 & 40.66 \\
19 & Pain & 81 & 35 & 43.21 \\
20 & Dermatology & 112 & 40 & 35.71 \\
21 & Traditional medicine & 83 & 35 & 42.17 \\
22 & Rehabilitation & 93 & 37 & 39.78 \\
& Total & 3,500 & 923 & 26.37 \\
\hline
\end{tabular}


environment; 18) diet management; 19) patient identification and 20) medical ethics. The internal consistency of the questionnaire was evaluated with Cronbach's $\alpha$ coefficient, which was calculated as 0.861 ; the test-retest reliability coefficient was 0.925 . Each item was assigned a level of $1-5$ according to the Likert 5-point subscale, with the choices set as "Very dissatisfied, Dissatisfied, Normal, Satisfied and Very satisfied"; 1-5-point range was used to indicate that the higher the score was, the higher the patient's evaluation of the hospital services. For the 20 items, the total possible score of patient satisfaction was 100 . The mean of all patient satisfaction scores was the overall hospital satisfaction rating.

Investigators from our center conducted field surveys and used electronic questionnaires to evaluate patient data. In the investigation, we strictly protected patient privacy and filled in answers anonymously. Patients unable to complete the evaluation (such as children and elderly patients) were represented by relatives or escorts. Investigators provided only guidance or interpretation services.

\section{Data processing and analysis}

Before the evaluation began, all investigators were trained. Site investigation was conducted in a manner to avoid contact with the hospital staff and to eliminate factors of human interference. Eligible questionnaires met the following standards: it took at least 1 minute for each questionnaire to be completed; in 10 minutes, three questionnaires were completed at the most; the sex of respondents to questionnaires concerning obstetrics and gynecology was limited to women; and the pediatric age was limited to patients under 18 years. After the data survey was completed, the data were automatically locked and stored.

The data were entered independently by EpiData 3.0 software. Data analysis was conducted using the SPSS statistical package version 22.0. Descriptive statistics were used for the sociodemographic data and inpatient satisfaction; continuous variables are presented as the mean and SD. One-way ANOVA and independent sample $t$-tests were used to compare differences in satisfaction with different groups. Multiple linear regression was used to analyze the relationship between demographic characteristics and overall satisfaction. The standardized regression coefficient (beta) with standard error (SE) was computed from the results of the linear regression analyses. Matrix analyses assessed the importance of the 20 items and the items that needed to be improved. The importance matrix analysis is a method for further subdividing the specific measurement indicators by combining the evaluation results of the specific measurement indicators and the degree of influence on patient satisfaction results. The degree of influence of each measurement index on patient satisfaction results and the patient evaluation of each measurement index are the vertical and horizontal axes, forming four regions and classifying specific measurement indexes. Significance for all comparisons was set at $P<0.05$.

\section{Results}

\section{Characterization of the sample}

Of the 923 respondents, 872 participated in this study, resulting in a response rate of $94.47 \%$. We excluded 51 respondents, 15 of whom were staff members of the hospital and 36 were relatives of hospital staff. In this sample, 457 patients were males (52.41\%), and most patients were distributed in the age range of $40-59$ years (304 patients, $34.86 \%$ ). Of the 872 participants, 696 were married $(79.82 \%)$ and 544 were junior middle graduates or less $(62.36 \%)$. Approximately $363(41.62 \%)$ had other jobs and 59.86\% earned between US\$ 0 and 4,782.79. Also, 716 (82.11\%) respondents lived in Shiyan and $369(42.32 \%)$ patients were admitted to the hospital for the first time. The characterization of the sample is shown in Table 2 .

\section{Twenty-item questionnaire regarding satisfaction with hospitalization care}

As shown in Table 3, the mean rate of satisfaction for different aspects of the 20 items ranged from 3.53 to 4.68 . Higher scores were given for emergency response $(4.68 \pm 0.66)$ and nurses' attitudes and skills (4.43 \pm 0.63$)$; lower scores were given for diet management (3.53 \pm 1.34$)$, medical expenses (3.78 \pm 0.93$)$ and complaint management (4.02 \pm 0.80$)$. By comparing the inpatient satisfaction questionnaires with the Greece and Indian tertiary hospitals, we found that the hospital's emergency response, protection of patient privacy, doctors' and nurses' attitudes, medical expenses and hospital environment scores were higher than those of the two countries.

\section{Overall satisfaction of patients with different demographic characteristics}

Table 4 lists the results of univariate analysis of the hospital satisfaction rate. Of the eight demographic characteristics, education status, occupation, annual income, residence and frequency of visits were significantly associated with overall satisfaction. The higher the degree of education, the higher was the satisfaction score $(F=5.165, P=0.006)$; employed satisfaction score was the highest $(F=3.196, P=0.013)$; the higher the income, the higher was the satisfaction $(F=3.52$, 
Table 2 Demographic characteristics ( $\mathrm{N}=872)$

\begin{tabular}{|c|c|c|}
\hline Variable & Frequency & Percentage \\
\hline \multicolumn{3}{|l|}{ Sex } \\
\hline Male & 457 & 52.41 \\
\hline Female & 415 & 47.59 \\
\hline \multicolumn{3}{|l|}{ Age group (years) } \\
\hline$<18$ & 92 & 10.55 \\
\hline $19-39$ & 170 & 19.50 \\
\hline $40-59$ & 304 & 34.86 \\
\hline $60-79$ & 247 & 28.33 \\
\hline$>80$ & 59 & 6.76 \\
\hline \multicolumn{3}{|l|}{ Marital status } \\
\hline Married & 696 & 79.82 \\
\hline Single or divorced and separated & 176 & 20.18 \\
\hline \multicolumn{3}{|l|}{ Education status } \\
\hline Junior middle graduate or less & 544 & 62.36 \\
\hline High school graduate & 213 & 24.45 \\
\hline College graduate or more & 115 & 13.19 \\
\hline \multicolumn{3}{|l|}{ Occupation } \\
\hline Farmer & 215 & 24.66 \\
\hline No job & 109 & 12.50 \\
\hline Retiree & 102 & 11.70 \\
\hline Others $^{\mathrm{a}}$ & 363 & 41.62 \\
\hline Employed & 83 & 9.52 \\
\hline \multicolumn{3}{|l|}{ Annual income ${ }^{\mathrm{b}}$ (US\$) } \\
\hline $0-4,782.79$ & 522 & 59.86 \\
\hline $4,782.79-|5,942.6|$ & 288 & 33.03 \\
\hline$|5,942.6|-3|, 885.2|$ & 49 & 5.62 \\
\hline$>31,885.21$ & 13 & 1.46 \\
\hline \multicolumn{3}{|l|}{ Residence } \\
\hline Shiyan & 716 & 82.11 \\
\hline Outside Shiyan & 156 & 17.89 \\
\hline \multicolumn{3}{|l|}{ Number of doctor visits ${ }^{c}$} \\
\hline First & 369 & 42.32 \\
\hline Fewer & 175 & 20.07 \\
\hline Numerous & 328 & 37.61 \\
\hline
\end{tabular}

Notes: a Others means freelancers and self-employed persons. ${ }^{\mathrm{b}}$ The values of annual income are converted from 0 to $30,000 \mathrm{RMB}$, from 30,000 to $100,000 \mathrm{RMB}$, from 100,000 to 200,000 RMB and $>200,000$ RMB. 'Number of doctor visits means the number of visits to the hospital; fewer refers to visiting the hospital twice and numerous refers to visiting three times and above.

Abbreviation: RMB, Renminbi.

$P=0.010)$; participants who lived outside Shiyan had higher scores than did local respondents $(t=-2.745, P=0.006)$; and regarding the frequency of visits, the fewer the number of visits, the lower was the score $(F=9.114, P=0.000)$. The multiple linear regression model displayed less collinearity among the independent variables and indicated good model fit (variance inflation factor $<5$, tolerance $>0.1$, $F=5.571, P<0.05$ ). Farmer was used as the control group, and employed, retiree, no job and other occupations were used as dummy variables using the Enter method. Other demographic variables were analyzed by stepwise method. Multiple linear regression analysis showed that the overall satisfaction score of patients increased with annual income.
Among them, if the annual income increased by one level, the patient satisfaction score increased by 1.370 . As the age increased by one level, the patient satisfaction score increased by 0.928 . The overall satisfaction score of the patients outside Shiyan was higher than that of the local patients of Shiyan, and the average patient satisfaction score was 2.551. As the level of education increased, the overall patient satisfaction score became higher; with each level of education increasing by one level, the patient satisfaction score increased by 1.109. The patient satisfaction score of employed subject was higher than that of farmer, with the average difference being 3.860; also, retiree's patient satisfaction score was higher than farmer satisfaction, with the average height being 2.953 Patient satisfaction scores in other occupations were higher than farmers' satisfaction, with the average difference being 2.654. There was no significant difference in the satisfaction scores between no job patients and farmer (Table 5).

\section{Importance matrix analysis}

The total satisfaction score of the patients was considered the dependent variable, and the score of the 20 items was regarded as the independent variable. The effect of the 20 items on the overall satisfaction of the patients was obtained by the partial least squares regression method. The result is shown in Table 2, and the importance matrix model is shown in Figure 1. Patient satisfaction scores form the abscissa, degree of influence is the ordinate, the median score $(\mathrm{X}=4.32, \mathrm{Y}=0.067)$ for patients and the degree of influence is the dividing line and the importance of inpatient satisfaction forms the matrix results (Figure 2). Priority should be given to improving the areas of diet management, medical expenses, complaint management, frequency of nurses' ward rounds, frequency of doctors' ward rounds, hospital environment and informed consent. These items have a relatively large impact on patient satisfaction, but the patients' evaluation of them is relatively low. Hospitals need to focus on improvement in these areas.

\section{Discussion}

In terms of inpatient satisfaction on a national level, the overall satisfaction score of inpatients in 136 sample Chinese hospitals was $93.1 \pm 5.7 .{ }^{21}$ In this paper, the overall satisfaction of hospitalized patients was $84.92 \pm 10.34$, which is lower than the values given in national reports. The reason for this gap is that the national surveys are conducted throughout the year and have sufficient time to track patients, avoiding the problem of insufficient sample size for short-term surveys. ${ }^{21}$ At the same time, the national survey chooses mainly hospitals from provincial capital cities and these hospitals provide 
Table 3 Twenty items used to calculate the mean patient satisfaction score (SD) and standardized coefficients (beta)

\begin{tabular}{|c|c|c|c|c|}
\hline Items & Mean score (SD) & Beta & Greece 2017 & India 2017 \\
\hline Admission process & $4.37(0.69)$ & 0.067 & $-^{\mathrm{d}}$ & - \\
\hline Frequency of doctors' ward rounds & $4.18(0.89)$ & 0.086 & - & - \\
\hline Frequency of nurses' ward rounds & $4.15(1.20)$ & 0.116 & - & - \\
\hline Emergency response & $4.68(0.66)$ & 0.064 & - & $3.87(0.34)$ \\
\hline Transparency & $4.39(0.66)$ & 0.064 & - & - \\
\hline Informed consent & $4.22(0.88)$ & 0.085 & - & - \\
\hline Protection of patient privacy & $4.35(0.67)$ & 0.064 & - & $3.87(0.33)$ \\
\hline Doctors' technical skill & $4.43(0.62)$ & 0.06 & - & - \\
\hline Nurses' technical skill & $4.43(0.63)$ & 0.068 & - & - \\
\hline Auxiliary examination & $4.09(0.82)$ & 0.061 & - & - \\
\hline Health education & $4.38(0.70)$ & 0.079 & - & - \\
\hline Doctors' attitudes toward service & $4.32(0.82)$ & 0.079 & $3.80(0.45)$ & $3.97(0.17)$ \\
\hline Nurses' attitudes toward service & $4.43(0.63)$ & 0.061 & $3.69(0.53)$ & $3.80(0.44)$ \\
\hline Overall service process & $4.36(0.66)$ & 0.064 & - & - \\
\hline Complaint management & $4.02(0.80)$ & 0.077 & - & - \\
\hline Medical expenses & $3.78(0.93)$ & 0.09 & - & $3.86(0.39)$ \\
\hline Hospital environment & $4.17(0.80)$ & 0.077 & $3.52(0.55)$ & $3.79(0.55)$ \\
\hline Diet management & $3.53(1.34)$ & 0.13 & - & - \\
\hline Patient identification & $4.31(0.64)$ & 0.062 & - & - \\
\hline Medical ethics & $4.33(0.62)$ & 0.06 & - & - \\
\hline Overall satisfaction & $84.92(10.34)$ & - & - & - \\
\hline
\end{tabular}

Note: dUnreported data

Table 4 Overall satisfaction of patients with different sociodemographic characteristics

\begin{tabular}{|c|c|c|c|c|c|}
\hline Variable & Frequency (n) & Percentage & $\begin{array}{l}\text { Overall satisfaction score } \\
\text { Mean } \pm \text { SD }\end{array}$ & $t / F$ & $P$-value \\
\hline Sex & & & & 0.746 & 0.456 \\
\hline Male & 457 & 52.41 & $85.17 \pm 10.00$ & & \\
\hline Female & 415 & 47.59 & $84.64 \pm 10.70$ & & \\
\hline Age group (years) & & & & 2.358 & 0.052 \\
\hline$\leq 18$ & 92 & 10.55 & $81.99 \pm 11.18$ & & \\
\hline $19-39$ & 170 & 19.50 & $84.62 \pm 11.45$ & & \\
\hline $40-59$ & 304 & 34.86 & $85.25 \pm 10.33$ & & \\
\hline $60-79$ & 247 & 28.33 & $85.55 \pm 9.94$ & & \\
\hline$\geq 80$ & 59 & 6.76 & $85.95 \pm 9.83$ & & \\
\hline Marital status & & & & -0.716 & $0.86 \mathrm{I}$ \\
\hline Married & 696 & 79.82 & $84.89 \pm 10.46$ & & \\
\hline Single or divorced and separated & 176 & 20.18 & $85.04 \pm 9.88$ & & \\
\hline Education status & & & & 5.165 & 0.006 \\
\hline Junior middle graduate or less & 544 & 62.36 & $84.39 \pm 10.82$ & & \\
\hline High school graduate & 213 & 24.45 & $84.74 \pm 9.19$ & & \\
\hline College graduate or more & 115 & 13.19 & $87.77 \pm 9.58$ & & \\
\hline Occupation & & & & 3.196 & 0.013 \\
\hline Farmer & 215 & 24.66 & $82.95 \pm 10.04$ & & \\
\hline No job & 102 & 12.50 & $84.50 \pm 10.43$ & & \\
\hline Retiree & 109 & 11.70 & $85.43 \pm 11.24$ & & \\
\hline Others & 363 & 41.62 & $85.63 \pm 10.20$ & & \\
\hline Employed & 83 & 9.52 & $86.80 \pm 9.87$ & & \\
\hline Annual income (US\$) & & & & 3.520 & 0.015 \\
\hline $0-4,782.79$ & 522 & 59.86 & $84.14 \pm 10.67$ & & \\
\hline 4,782.79-I5,942.6I & 288 & 33.03 & $85.77 \pm 9.88$ & & \\
\hline$|5,942.6|-3|, 885.2|$ & 49 & 5.62 & $86.7 I \pm 8.98$ & & \\
\hline$>31,885.21$ & 13 & 1.46 & $90.69 \pm 7.67$ & & \\
\hline Residence & & & & -2.745 & 0.006 \\
\hline Shiyan & 716 & 82.11 & $84.47 \pm 10.44$ & & \\
\hline Outside Shiyan & 156 & 17.89 & $86.97 \pm .60$ & & \\
\hline Frequency of visits & & & & 9.114 & 0.000 \\
\hline First & 369 & 42.32 & $82.25 \pm 10.45$ & & \\
\hline Fewer & 175 & 20.07 & $84.91 \pm 9.82$ & & \\
\hline Numerous & 328 & 37.61 & $86.34 \pm 10.58$ & & \\
\hline
\end{tabular}


Table 5 Multiple stepwise regression analysis of the risk factors affecting overall satisfaction score $(\mathrm{N}=872)$

\begin{tabular}{l|l|l|l|l|l|l|l}
\hline Variables & $\boldsymbol{\beta}$ & $\begin{array}{l}\text { Standard } \\
\text { error }\end{array}$ & $\begin{array}{l}\text { Standardized } \\
\text { coefficients (beta) }\end{array}$ & $\boldsymbol{t}$ & $\boldsymbol{P}$-value & $\boldsymbol{F}$ & $\boldsymbol{P}$-value \\
\hline (Constant) & 79.362 & 1.021 & & 77.744 & 0.000 & 5.571 & 0.000 \\
Annual income & 1.370 & 0.531 & 0.089 & 2.579 & 0.010 & \\
Age & 0.928 & 0.318 & 0.097 & 2.918 & 0.004 & \\
Residence & 2.551 & 0.902 & 0.095 & 2.830 & 0.005 & \\
Education status (control: farmer) & 1.109 & 0.494 & 0.077 & 2.245 & 0.025 & \\
Employed & 3.860 & 1.312 & 0.110 & 2.943 & 0.003 & \\
Retiree & 2.953 & 1.221 & 0.092 & 2.418 & 0.016 & \\
No job & 1.454 & 1.195 & 0.047 & 1.217 & 0.224 & & \\
Others & 2.654 & 0.872 & 0.127 & 3.043 & 0.002 & & \\
\hline
\end{tabular}

higher quality medical services for patients. ${ }^{21}$ Therefore, the data of this study are lower than the national report. Among the questionnaire items, emergency response, protection of patients' privacy, doctors' and nurses' attitudes, medical expenses and hospital environment scored higher than the tertiary hospital score from India and Greece. ${ }^{22,23}$ It shows that the quality of medical services in this study is not worse than in other countries. Due to the different questionnaire and scoring methods, our data cannot be fully compared with other countries; this is normal and cannot be avoided. We also assessed the sociodemographic variations across overall inpatient satisfaction. Through univariate analysis, we found that education, occupation, income, residence and frequency of hospital visits were directly related to overall satisfaction. The higher the level of education, the better was the understanding of medical knowledge and the positive evaluation of medical and health services. ${ }^{24,25}$ In contrast, patients with lower levels of education have limited access to information and cannot form an objective understanding of medical services, resulting in reduced satisfaction. ${ }^{24}$ This analysis showed that the place where people reside can have some impact on patients' perception of care, ${ }^{26}$ as inpatients who were residents of Shiyan rated their care more poorly than did patients residing outside of Shiyan. These patients may have higher expectations for their care because of a perception of choice. These data also suggested that the frequency of visits is positively related to their experience. Perhaps, a more notable finding of this study is that as the frequency of visits increased, ${ }^{27}$ the more favorably the patients perceived the hospital environment and services.

The results of multiple linear regression analysis showed that annual income, age, residence and occupation affected satisfaction. Annual income is closely related to overall satisfaction. ${ }^{28}$ The reason may be that the lowincome inpatients are unable to bear the treatment costs of the tertiary hospitals, and the medical charges are expected to be too low, so the satisfaction is relatively low. Previous work has suggested that patient age is important

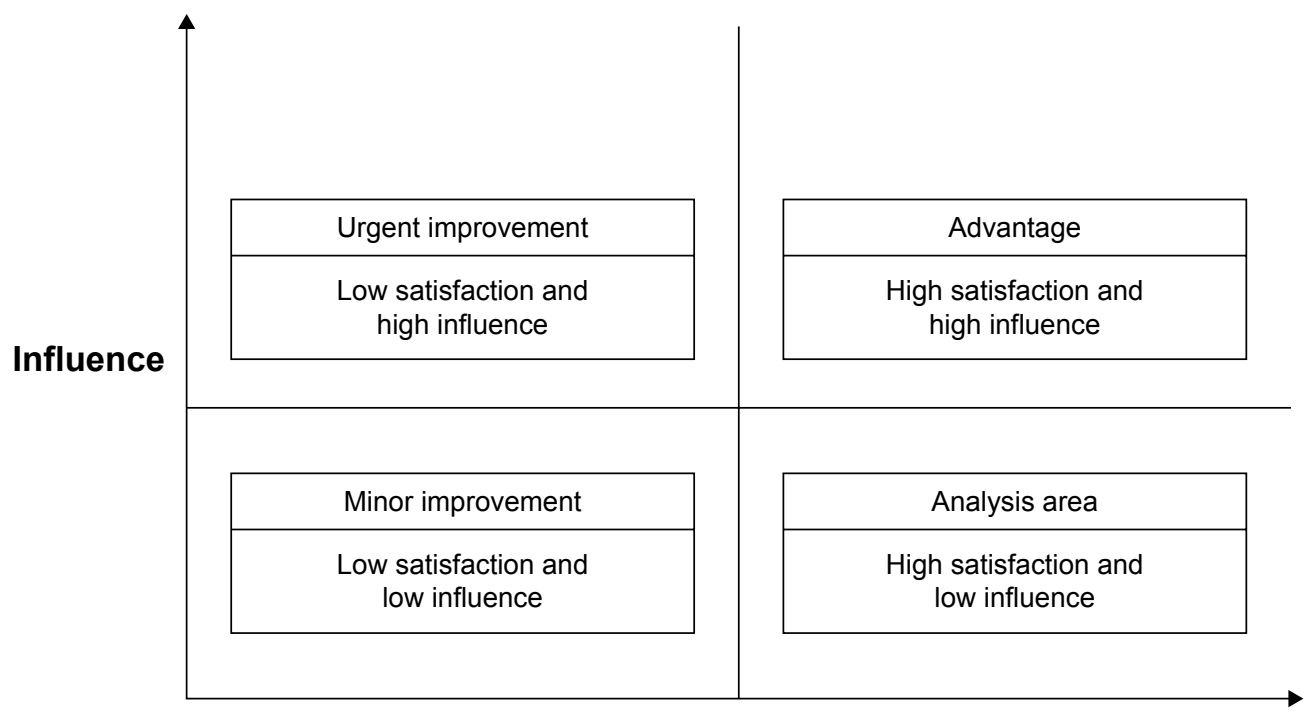

Patient evaluation

Figure I The importance matrix analysis modeling method. 


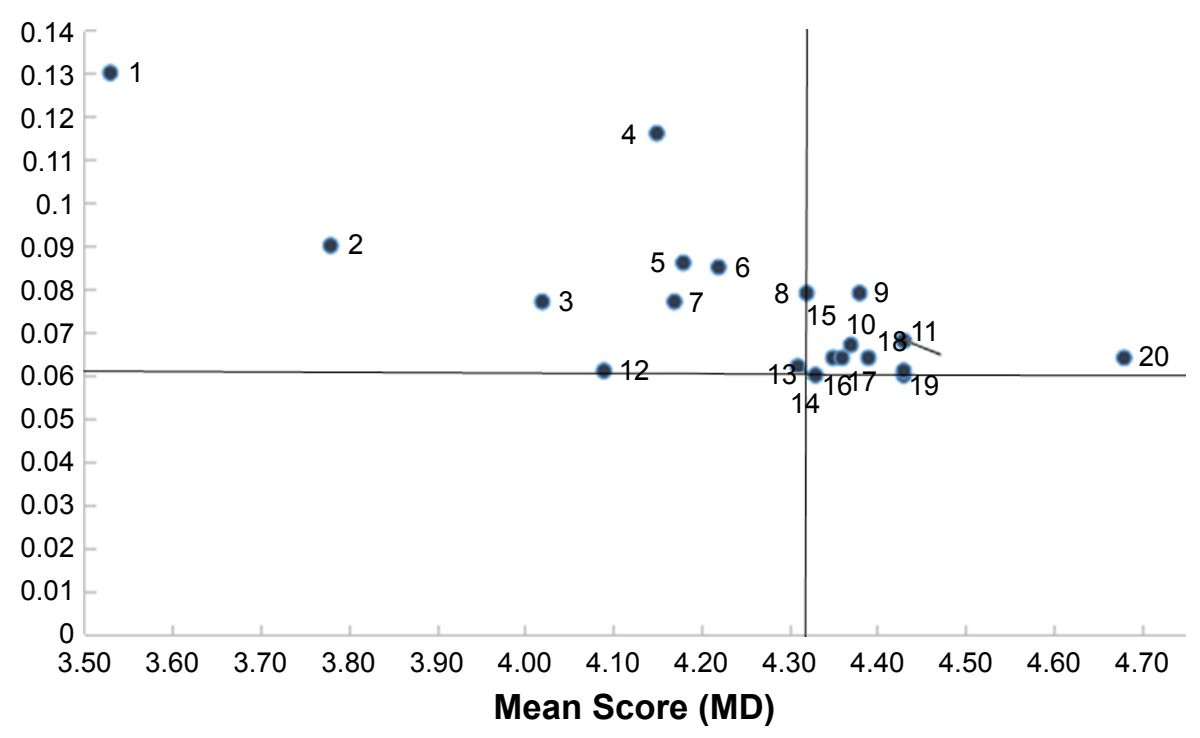

Figure 2 The importance matrix analysis of inpatient satisfaction.

Notes: (I) Diet management; (2) Medical expenses; (3) Complaint management; (4) Frequency of nurses' ward rounds; (5) Frequency of doctors' ward rounds; (6) Informed consent; (7) Hospital environment; (8) Doctors' service attitude; (9) Health education; (10) Admission process; (11) Nurses' technical skill; (I2) Auxiliary examination; (13) Patient identification; (14) Medical ethics; (15) Patients' privacy protection; (16) Overall service process; (I7) Transparency; (I8) Nurses' service attitude; (19) Doctors' technical skill; (20) Emergency response.

because of the increasing number of elderly patients due to demographic changes. ${ }^{29}$ Another research has shown that older patients have a lower desire to be involved in medical decision making due to the information asymmetry between doctors and patients. ${ }^{30}$ This study showed that age plays an important role in satisfaction. Patient satisfaction increased by 0.928 for each group of age. The older the age, the richer the social experience, the easier it is to communicate, so the satisfaction is higher. These findings suggest that the effect of occupation on patient satisfaction may indicate that farmers and no job patients have relatively few resources and information, and that the demand for medical services cannot be satisfied in time. Occupation, education and income are usually related; ${ }^{31}$ farmers' education and income levels are low and their experience in medical services is poor.

According to the results of matrix analysis, diet management, medical expenses, complaint management, the frequency of nurses' ward rounds, the frequency of doctors' ward rounds, hospital environment and informed consent earned relatively low levels of satisfaction. During the questionnaire survey, patients reported that dissatisfaction with diet management mainly focused on dietary quality, taste, price and canteen staff service attitude. The patient's expectation is more that the hospital should provide healthy, reasonably priced, delicious food, and they expect the canteen staff to maintain quality service. Due to eating habits, environmental changes and the effects of diseases and drugs, the patients' taste changes, and loss of appetite affects patients' recognition of the hospital diet. The hospital logistics department should establish a "patient-centered" service concept based on the patients' eating habits, tastes, preferences and disease treatment principles, in order to develop a balanced diet and to meet the needs of treatment. Every day, the hospital logistics department should communicate with patients, understand the needs of patients, collect opinions and suggestions from patients and improve service levels.

Although the People's Republic of China started a new round of medical reform ${ }^{32}$ in 2009 , this change has not effectively alleviated the difficult problem of unaffordable health care services. Public hospital reform has not yet made a breakthrough and has failed to reverse profit-making behavior. Shiyan is located in a contiguous destitute area of People's Republic of China. The living environment and economic conditions of residents are relatively poor. The urban-rural dualistic social system in People's Republic of China divides medical insurance into competing plans: Basic Medical Insurance for Urban Residents and New Rural Cooperative Medical Insurance. ${ }^{33,34}$ Under the current policy, the New Rural Cooperative Medical Insurance reimbursement ratio is lower than that for Basic Medical Insurance for Urban Residents. The current medical insurance system in People's Republic of China can guarantee only the basic compensation level, and the economic burden of the patients is still heavy. ${ }^{35}$ This situation also reflects the imperfection of the Chinese medical system and the lack of protection regarding the government-endorsed right to the health of the people. 
In this study, income accounted for $92.89 \%$ of the lowest two levels. Compared with high-income patients, low-income patients were more concerned about hospitalization costs, which is consistent with the results of multivariate analysis. Therefore, the hospital should consider patients' medical insurance, economic conditions and other factors. From the perspective of improving the curative effect of a hospital stay, the hospital should enhance the patients' perception of cost-effectiveness.

Despite the remarkable achievements made in Chinese medical and health services, there is still a crisis regarding trust between patients and doctors. ${ }^{36}$ Medical complaints are divided into patients' dissatisfaction with hospital's attitudes about service, medical quality, business level, lack of patient understanding (dissatisfaction, lack of communication) and other types. ${ }^{37}$ Complaints are best understood as sentinel events, ${ }^{38}$ and the patients' cognitive state and complaint psychology can be understood. Complaints about quality of service mainly involve impatience and apathy among medical staff, instances of consultations being postponed, a lack of attention to protecting patient privacy and irregular medical treatment. Overall, complaints are mainly directed toward the main clinical care staff categories, doctors and nurses. ${ }^{39}$ Due to poor communication, staff attitudes and nursing services have caused a large number of complaints. The survey showed that the hospital did not pay enough attention to the patient's demands, and the effect made the patient unsatisfied. Patient expectations include admitting an error if an error was made, ${ }^{40,41}$ explaining to the patient the reason for the interpretation of the incident, notifying the rectification to the relevant department, ${ }^{42}$ providing measures and apologizing to the patient. The best response to a complaint does not always need to be expressed in a sorry or sympathetic tone, or if the complaint becomes unfounded, there may not be a need to provide actual support or take action. In most cases, ${ }^{43}$ hospital managers will respond to complaints with informational medical devices. In People's Republic of China, ${ }^{44}$ managers are administrative staff rather than clinical staff. Clinical complaints handled by doctors may be affected by conflicts of interest, so they are reluctant to admit they are wrong. Regardless of the complaints, hospital managers are reluctant to admit that their hospital was wrong.

Patient satisfaction with nursing work is regarded as a sensitive indicator of nursing outcomes. ${ }^{45}$ Previous studies have shown that nurses' optimistic moods will contribute to patients feeling more positive emotionally. ${ }^{46}$ Sahu's $^{47}$ research points out that nurses who engaged in rotating shift work, especially night work, were the most prone to impairment of work efficiency, which affected patient experience. The Lancet reported that ${ }^{48}$ the shortage of human resources for nurses in People's Republic of China cannot be changed in the short term. Patients' dissatisfaction with the frequency of the nurses' ward may be due to the lack of sufficient time for the nurse to work in the ward and to communicate with the patient. In addition, accidents have caused nurses to leave the ward round halfway, which results in the ward round being interrupted. Factors such as rescuing patients and urgent examinations will also affect the evaluation of the patients concerning the nursing ward rounds. ${ }^{49}$

Similar to our findings regarding nurses, we found that patients were also not satisfied with the doctors' ward rounds. Doctor-patient communication contributes to medical quality and patient safety. ${ }^{50,51}$ The ward round is an important opportunity for communication between doctors and patients. ${ }^{52,53}$ It helps develop an understanding about the patient's condition and provides an opportunity to discuss a diagnosis and treatment plan. Patients hope doctors will come to them during rounds because they will hear news of their progress ${ }^{54}$ and, perhaps, whether they can go home. Moreover, even if doctors communicate with each patient for roughly the same time, patients still feel that they lack individual attention. ${ }^{55}$ Doctors should make ward rounds at least two times a day (data from Chinese third-level general hospital accreditation standards). ${ }^{56}$ In this study, the frequency of ward rounds was only once daily. Therefore, the doctor should conduct ward rounds at least two times a day; according to the patient's condition, changes can be made to adjust the doctor's orders, thus improving the patient's condition and providing patients with effective treatment.

The hospital environment refers to the environment of health care and is an important factor that affects the physical and mental comfort of the patient. ${ }^{57}$ The hospital environment includes an appropriate temperature, a clean ward and a reasonable sound level. Studies have shown that environmental factors are an important part of patients' overall medical experience. ${ }^{58}$ The evaluation criteria of the patients' service quality are mainly based on the results they expect compared with the services they actually received. The environment is the first impression the patient has of the medical process. In this study, patients were not satisfied with the hospital environment. It may be because the hospital did not provide patients with certain convenient and comfortable equipment.

Several studies have shown that written information has a beneficial effect. ${ }^{59}$ Evidence regarding the patientcentered concept suggests that providing patients with adequate information such as informed consent encourages 
the patients' cooperation. ${ }^{60,61}$ In our study, many patients did not receive verbal notifications from doctors. The patients felt anxious on the day before surgery, which is consistent with previous research. ${ }^{51}$ Therefore, medical staff should choose to give verbal and written informed consent to reduce the patients' psychological stress.

This study has some limitations. First, the sample covers only the main departments, and subsequent investigations should expand the departments and samples. Second, since the number of beds in each department is different from the actual number of patients in the hospital, the proportion of the department is not exactly the same, which is inevitable during the investigation. Third, in the process of training the investigators, it is inevitable that there will be differences in the understanding of the contents of the questionnaire.

\section{Conclusion}

This study found that the hospital still needs further improvements. Age, education, occupation, income, residence and frequency of visits were the demographic characteristics that affected inpatient satisfaction; medical expenses, attitudes concerning service and patients' rights and interests were the continued themes of hospital quality management. The hospital manager should use the Patient Satisfaction Survey platform to obtain valuable information and continually optimize medical services, thus improving patient satisfaction and medical service quality.

\section{Acknowledgment}

This project was supported by the National Natural Science Foundation of China (71774049).

\section{Disclosure}

The authors report no conflicts of interest in this work.

\section{References}

1. Minsheng F, Lin Z. Relationship between health care policy and doctors and patients. Med Philos. 2004;25(9):9-11.

2. Lankun Z. The impact of changes in doctor-patient relationship on medical work under market economy conditions. J Ningxia Soc Sci. 1998;5:64-70.

3. Shuizhen W, Zengping C, Yongping Q. Building a harmonious relationship between doctors and patients and enhancing hospital brand competitiveness. Chin J Hosp Manag. 2009;29(9):54.

4. Chinese doctor practice status white paper [homepage on the Internet] Beijing: Chinese medical doctor association; 2015 [updated May 28, 2015]. Available from: http://www.cmda.net/zlwqtzgg/10578.jhtml. Accessed September 3, 2018.

5. Mcfarland DC, Shen MJ, Parker P, Meyerson S, Holcombe RF. Does hospital size affect patient satisfaction? Qual Manag Health Care. 2017; 26(4):205-209.

6. Wu H, Lu N. Service provision, pricing, and patient satisfaction in online health communities. Int J Med Inform. 2018;110:77-89.
7. Brosig-Koch J, Hehenkamp B, Kokot J. The effects of competition on medical service provision. Health Econ. 2017;26(9):6-20.

8. Stålnacke BM, Elgh E, Sojka P. One-year follow-up of mild traumatic brain injury: cognition, disability and life satisfaction of patients seeking consultation. J Rehabil Med. 2007;39(5):405-411.

9. Carretta E, Bond TG, Cappiello G, Fantini MP. Looking through the patients' eyes: measuring patient satisfaction in a public hospital. J Patient Exp. 2017;4(3):121-128.

10. Guoxian B, Zhidong Z. Analysis on the self-discipline of the third party government performance evaluation organization in China. Chin Admin Manag. 2008;1:49-51.

11. Li Qing LY, Jun Z. Analysis on the construction of third party hospital evaluation system. Hosp Managt Forum. 2016;33(10):11-14.

12. Kezhen L, Tingfang L. Research on the construction of third party evaluation model of medical institutions in China. Chin Hosp. 2016;20(05):42-44.

13. Maghen R, Pascual R, Trombley L. Patient satisfaction scores: a comparison between internal and third-party measurement tools. $J$ Am Diet Assoc. 2011;111(9):A58.

14. Zeng Y, Li S. Application of Third Party Evaluation in Hospital Patient Satisfaction Survey. Hosp Manag Forum. 2014;31(7): 24-26.

15. Zhao Y, Liu Y, Hou P. The effect of third-party satisfaction investigation into the performance evaluation on medical service. Chin J Guangming Med. 2017;32(8):1206-1208.

16. Ting C. Empirical research on third-party evaluation of medical service quality in China [D]. Tianjin University of Finance and Economics; 2013.

17. Chunxiao H. Third-party evaluation of patient satisfaction in public hospitals in Chongqing [D]. Chongqing Medical University; 2015.

18. Chuan-Ji G, Ming-Zhe WU, Jian-Fei SHI. Objective evaluation of patient satisfaction with third-party evaluation. Chin J Mod Hosp Admin. 2007;5(2):26-28.

19. National Health and Family Planning Commission of the People's Republic of China Notice on Printing and Issuing Action Plan for Further Improving Medical Services [homepage on the Internet] Beijing: National Health Commission of the People's Republic of China; 2015 [updated January 28, 2015]. Available from: http://www.nhfpc.gov. cn/yzygj/s3593g/201501/5584853cfa254d1aa4e38de0700891 fa.shtml. Accessed March 13, 2018.

20. Economic and Social Development Database [homepage on the Internet] Shiyan: Shiyan city government; 2018 [updated April 10, 2018]. Available from: http://www.shiyan.gov.cn/sysgovinfo/szf/ xxgkml/tjxx_7676/tjbg/201804/t20180410_1362133.shtml. Accessed September 4, 2018.

21. Yuanli L, Jing S, Hu Guangyu ETC. Third-party assessment of the improvement of medical services nationwide survey. Chin J Hosp Admin. 2016;32(6):404-409.

22. Shekhawat $\mathrm{S}$, Garg $\mathrm{S}$, Jain D. Inpatient satisfaction level survey at a tertiary care hospital. Int J Res Med Sci. 2016;5(1):240-244.

23. Xesfingi S, Karamanis D, Vozikis A. Patient satisfaction at tertiary level healthcare services in Greece: inpatient vs outpatient healthcare services assessment. Int J Health Econ Policy. 2017;2(3):125-133.

24. Baltaci D, Eroz R, Ankarali H. Association between patients' sociodemographic characteristics and their satisfaction with primary health care services in Turkey. J Kuwait Med Assoc. 2013;45(4):291-299.

25. Al-Borie HM, Damanhouri AM. Patients' satisfaction of service quality in Saudi hospitals: a SERVQUAL analysis. Int J Health Care Qual Assur. 2013;26(1):20-30.

26. Levinton C, Veillard J, Slutsky A, Brown A. The importance of place of residence in patient satisfaction. Int J Qual Health Care. 2011;23(5): 495-502.

27. Cho WH, Lee H, Kim C, Lee S, Choi KS. The impact of visit frequency on the relationship between service quality and outpatient satisfaction: a South Korean study. Health Serv Res. 2004;39(1):13-34.

28. Heaton HA, Castaneda-Guarderas A, Trotter ER, Erwin PJ, Bellolio MF. Effect of scribes on patient throughput, revenue, and patient and provider satisfaction: a systematic review and meta-analysis. Am J Emerg Med. 2016;34(10):2018-2028. 
29. Peck BM. Age-related differences in doctor-patient interaction and patient satisfaction. Curr Gerontol Geriatr Res. 2011;2011(11):1-10.

30. Greene MG, Adelman RD, Friedmann E, Charon R. Older patient satisfaction with communication during an initial medical encounter. Soc Sci Med. 1994;38(9):1279-1288.

31. Akhtarizavare M, Abdullah MY, Abdullah MY. Patient satisfaction: evaluating nursing care for patients hospitalized with cancer in Tehran teaching hospitals, Iran. Glob J Health Sci. 2010;2(1):117-126.

32. Husain L. Policy experimentation and innovation as a response to complexity in China's management of health reforms. Global Health. 2017; 13(1):54

33. Feng Y, Li S, Wu Z. The study of the rational allocation of China's human resources for health. Stud Soc Sci. 2014;1(2):100-106.

34. Shan L, Zhao M, Ning N, et al. Dissatisfaction with current integration reforms of health insurance schemes in China: are they a success and what matters? Health Policy Plan. 2018;33(3):345-354.

35. Wang C, Rao K, Wu S, Liu Q. Health care in China: improvement, challenges, and reform. Chest. 2013;143(2):524-531.

36. Nie JB, Cheng Y, Zou X, et al. The vicious circle of patient-physician mistrust in China: health professionals' perspectives, institutional conflict of interest, and building trust through medical professionalism. Dev World Bioeth. 2018;18(1):26-36.

37. Stelfox HT, Gandhi TK, Orav EJ, Gustafson ML. The relation of patient satisfaction with complaints against physicians and malpractice lawsuits. Am J Med. 2005;118(10):1126-1133.

38. Obermair A, Janda M, Gebski V, Bismark MM, Spittal MJ, Gurrin LC. Identification of doctors at risk of recurrent complaints: a national study of healthcare complaints in Australia. BMJ Qual Saf. 2013;22(10) 878 .

39. Siyambalapitiya S, Caunt J, Harrison N, White L, Weremczuk D, Fernando DJ. A 22 month study of patient complaints at a National Health Service hospital. Int J Nurs Pract. 2007;13(2):107-110.

40. Friele RD, Sluijs EM, Legemaate J. Complaints handling in hospitals: an empirical study of discrepancies between patients' expectations and their experiences. BMC Health Serv Res. 2008;8:199.

41. Friele RD, Sluijs EM. Patient expectations of fair complaint handling in hospitals: empirical data. BMC Health Serv Res. 2006;6:106.

42. Veneau L, Chariot P. How do hospitals handle patients complaints? An overview from the Paris area. J Forensic Leg Med. 2013;20(4): 242-247.

43. Chou Y C, Chen C L, Wu T H. Medical device on pharmacists' workrelated musculoskeletal complaints and burnouts. Ergonomics. 2012; 55(11):1420-1428

44. Xiaoqin C, Jiani Q, Yi W. Practice and discussion of medical complaint management service model innovation. Chin Hosp. 2012;16(3): 63-65.

45. Goh ML, Enk A, Chan YH, He H-G, K Vehvilainen-Julkunen. Patient satisfaction is linked to nursing workload in a Singapore hospital. Clin Nurs Res. 2017;27(6):692-713.
46. Oyur Celik G, Celik LO. The relationship between patient satisfaction and emotional intelligence skills of nurses working in surgical clinics. Patient Prefer Adherence. 2017;11:1363-1368.

47. Sahu S. Occupational stress and work efficiency of nursing staff engaged in rotating shift work. Biol Rhythm Res. 2015;46(4):511-522.

48. Anand S, Fan VY, Zhang J, et al. China's human resources for health: quantity, quality, and distribution. Lancet. 2008;372(9651):1774-1781.

49. Jie B, Liu Yu LX. Analysis of the factors that promote and hinder nurses from participating in medical rounds. Chin Nurs Manage. 2015; 15(5):536-539.

50. Fossli Jensen B, Dahl FA, Safran DG, et al. The ability of a behaviourspecific patient questionnaire to identify poorly performing doctors. BMJ Qual Saf. 2011;20(10):885-893.

51. Mcalinden C. The importance of doctor-patient communication. $\mathrm{Br} J$ Hosp Med. 2014;75(2):64-65.

52. Alsos OA, Dabelow B, Faxvaag A. Doctors' concerns of PDAs in the ward round situation. Lessons from a formative simulation study. Methods Inf Med. 2011;50(2):190-200.

53. Powell N, Bruce CG, Redfern O. Teaching a 'good' ward round. Clin Med (Lond). 2015;15(2):135-138.

54. Launer J. What's wrong with ward rounds? Postgrad Med J. 2013; 89(1058):733-734.

55. Tariq M, Motiwala A, Ali SU, Riaz M, Awan S, Akhter J. The learners' perspective on internal medicine ward rounds: a cross-sectional study. BMC Med Educ. 2010;10(1):1-9.

56. Chinese third-level general hospital accreditation standards [homepage on the Internet] Beijing: National Health Commission of the People's Republic of China; 2013 [updated April 4, 2013]. Available from:http:// www.nhfpc.gov.cn/zwgk/wtwj/201304/0404f9cd71764ab29b2365e06 9cfbf2d.shtml. Accessed June 4, 2018.

57. Johansson P, Oléni M, Fridlund B. Patient satisfaction with nursing care in the context of health care: a literature study. Scand J Caring Sci. 2002;16(4):337-344.

58. Shrestha N, Mongkolchati A, Rattanapan C. Assessment of patient satisfaction at a traditional medicine hospital in Nepal. J Bacteriol. 2012;194(16):4377-4385.

59. Ghulam AT, Kessler M, Bachmann LM, Haller U, Kessler TM. Patients' satisfaction with the preoperative informed consent procedure: a multicenter questionnaire survey in Switzerland. Mayo Clin Proc. 2006;81(3) 307-312.

60. Brandel MG, Reid CM, Parmeshwar N, Dobke MK, Gosman AA. Efficacy of a procedure-specific education module on informed consent in plastic surgery. Ann Plast Surg. 2017;78(5 Suppl 4):1.

61. Kinnersley P, Phillips K, Savage K, et al. Interventions to promote informed consent for patients undergoing surgical and other invasive healthcare procedures. Cochrane Database Syst Rev. 2013;7(7): CD009445.
Patient Preference and Adherence

\section{Publish your work in this journal}

Patient Preference and Adherence is an international, peer-reviewed, open access journal that focuses on the growing importance of patient preference and adherence throughout the therapeutic continuum. Patient satisfaction, acceptability, quality of life, compliance, persistence and their role in developing new therapeutic modalities and compounds to optimize

\section{Dovepress}

clinical outcomes for existing disease states are major areas of interest for the journal. This journal has been accepted for indexing on PubMed Central. The manuscript management system is completely online and includes a very quick and fair peer-review system, which is all easy to use. Visit http://www. dovepress.com/testimonials.php to read real quotes from published authors. 